\title{
A spatiotemporal optimization model for the evacuation of the population exposed to flood hazard
}

\author{
H. Alaeddine ${ }^{1,2}$, K. Serrhini ${ }^{1}$, M. Maizia ${ }^{1}$, and E. Néron ${ }^{2}$ \\ ${ }^{1}$ Laboratoire Citères de l'Université de Tours, Tours, France \\ ${ }^{2}$ Laboratoire Informatique de l'Université de Tours, Tours, France \\ Correspondence to: H. Alaeddine (houssein.alaeddine@ hotmail.fr)
}

Received: 2 December 2014 - Published in Nat. Hazards Earth Syst. Sci. Discuss.: 5 January 2015

Revised: - - Accepted: 11 March 2015 - Published: 30 March 2015

\begin{abstract}
Managing the crisis caused by natural disasters, and especially by floods, requires the development of effective evacuation systems. An effective evacuation system must take into account certain constraints, including those related to traffic network, accessibility, human resources and material equipment (vehicles, collecting points, etc.). The main objective of this work is to provide assistance to technical services and rescue forces in terms of accessibility by offering itineraries relating to rescue and evacuation of people and property. We consider in this paper the evacuation of an urban area of medium size exposed to the hazard of flood. In case of inundation, most people will be evacuated using their own vehicles. Two evacuation types are addressed in this paper: (1) a preventive evacuation based on a flood forecasting system and (2) an evacuation during the disaster based on flooding scenarios. The two study sites on which the developed evacuation model is applied are the Tours valley (Fr, 37 ), which is protected by a set of dikes (preventive evacuation), and the Gien valley (Fr, 45), which benefits from a low rate of flooding (evacuation before and during the disaster). Our goal is to construct, for each of these two sites, a chronological evacuation plan, i.e., computing for each individual the departure date and the path to reach the assembly point (also called shelter) according to a priority list established for this purpose. The evacuation plan must avoid the congestion on the road network. Here we present a spatiotemporal optimization model (STOM) dedicated to the evacuation of the population exposed to natural disasters and more specifically to flood risk.
\end{abstract}

\section{Introduction}

This paper addresses the problem of the evacuation of people exposed to a risk of flooding. Arranged with specific urban databases (flooding scenarios, census of population, transport network, etc.), the model developed here enables us to compute the evacuation routes to be taken by the affected population while minimizing the total evacuation time. This optimization model must take into account several constraints, such as accessibility (Geurs and Wee, 2004; Chapelon and Leclerc, 2007; Mathis et al., 2007), roads capacity, capacity of safe areas, vulnerability of the population exposed to risk (lists of priorities, scheduling) and vulnerability of transport network (roads cut during floods) (Fuchs et al., 2007; Plattner, 2005; Matisziw and Murray, 2009; Caloz and Collet, 2011).

The occurrence time of a flood event is known in advance (at least $48 \mathrm{~h}$ before), a period during which the population concerned should exit the area (Patouillard et al., 2013). The evacuation process must be prepared, i.e., fixing a departure date and escape route for each household to the associated safe area.

The evacuation of stakes (buildings, nuclear centers, hospitals, etc.) exposed to natural hazards (floods, earthquakes, tornadoes, volcanoes, tsunamis, etc.) was and is a problem that occupies a high position in the hierarchy of priorities of governments of multiple countries. The US Department of Homeland Security defines the evacuation of an area as "the organized, phased, and supervised withdrawal, dispersal, or removal of civilians from dangerous or potentially dangerous areas, and their reception and care in safe areas" (National Incident Management System, December 2008, p. 139). 


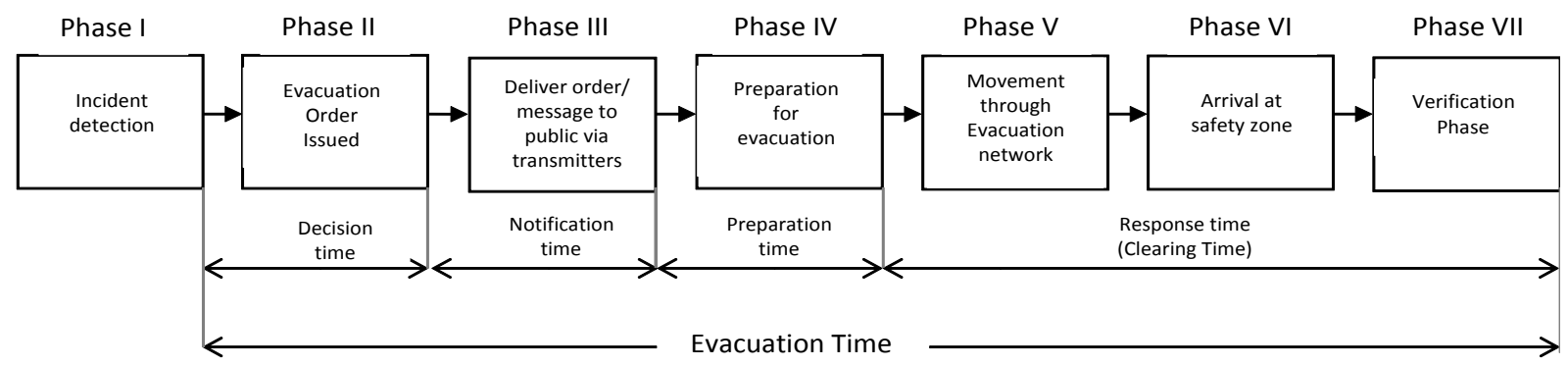

Figure 1. Phases of the evacuation process (Stepanov and Smith, 2009).

The evacuation of areas prone to natural (such as floods) or technological (such as nuclear risk) hazards can be one of the measures for the protection of urban issues. It requires systems and decision support tools mainly to protect the lives of people. The reorganization of routing traffic in densely populated areas is a very important element for a massive emergency evacuation. Safety and minimization of delays and total travel time are the main aspects to be taken into account during an evacuation. This reorganization of the traffic can be modeled and solved by tools of operations research (Bretschneider and Kimms, 2012).

The total evacuation time can be defined as the time needed for an evacuation process that includes the warning time, preparation time, travel time between dangerous and safe areas and evacuation verification time (Bretschneider and Kimms, 2012; Hamacher and Tjandra, 2001). Stepanov and Smith (2009) show that the complex process of evacuation includes several consecutive phases (see Fig. 1).

Missions and necessary tasks need to be coordinated among government and nongovernmental organizations (Bretschneider and Kimms, 2012). The realization phase itself consists of evacuating the affected population through the network prepared for this purpose. This includes the paths computed from areas to be evacuated (buildings, neighborhoods, etc.) to safety areas (shelters, assembly points, etc.). Transportation planning that includes the design and the evaluation of transport infrastructure (highways, streets, public transport routes, etc.) is required to ensure that the entire population exposed to hazard has the opportunity to safely leave the risk zone. This includes the planning of routing and the organization of traffic circulation on evacuation routes. As only a part of the population is evacuated using their own vehicles, adequate transportation must be provided for the other part of the population (e.g., nursing homes, hospitals, prisons).

Since 1960 many studies have been conducted in the fields of optimization and evacuation planning. Those works can be grouped into two: the optimization approaches of an evacuation plan with specific objectives and the evaluation process of existing evacuation plans to check and validate them. While validation approaches are usually of the microscopic type, optimization approaches are rather macroscopic (dy- namic network flow) or microscopic (traffic assignment) and manage the evacuees' movements over time. Contrary to microscopic models (Naghawi, 2010; Lammel et al., 2010; Powell et al., 1995), the macroscopic methods (Yusoff et al., 2008; Bretschneidera and Kimms, 2011; Saadatsresht et al., 2009) do not take into account human behavior and interaction between vehicles. Indeed, evacuees are treated as a homogenous group where only common characteristics are considered. These methods tend to minimize the total evacuation time. Between the two previous levels (macroscopic and microscopic), the mesoscopic methods (Naser and Birst, 2011; Dixit, 2005; Bormanna et al., 2012) allow us to follow in real time the trajectory of each vehicle (its position in the network). However, these methods do not take into account either the behavior of evacuees or the interaction of vehicles with their environment.

We are interested in a spatiotemporal optimization model $(\mathrm{STOM})^{1}$ to develop a two-stage mesoscopic model combining dynamic network flow and traffic assignment models. This choice is a trade-off between the accuracy of the microscopic model and the application of the macroscopic one (modeling of large networks). The first stage concerns the development of an evacuation scheduling system based on an established priority list, where we evacuate, at each time slot $(1 \mathrm{~h}, 0.5 \mathrm{~h}$, etc.) and by priority order, the maximum number of vehicles from each building not yet totally evacuated. Roads capacity, predetermined evacuation paths and destination capacity must be respected during the assignment of flow. Based on this result, a vehicles pursuit model (VPM) is also developed in order to, first, convert the discrete process (time slots) to a continuous one (time intervals) and, second, avoid overlap between successive time intervals. This overlap may occur on network roads because the sources from which flow is outgoing (incoming to network roads) at each time slot vary over time. VPM minimizes the evacuation departure times of buildings. The flow-dependent travel time on roads is computed using a polynomial traffic model (Ardekani et al., 2011; Trani, 2009) which is also used to compute the capacity (maximal flow rate) on roads based

\footnotetext{
${ }^{1}$ This study is a part of ACCELL project funded by "la Région Centre, France" and the European Union (FEDER).
} 


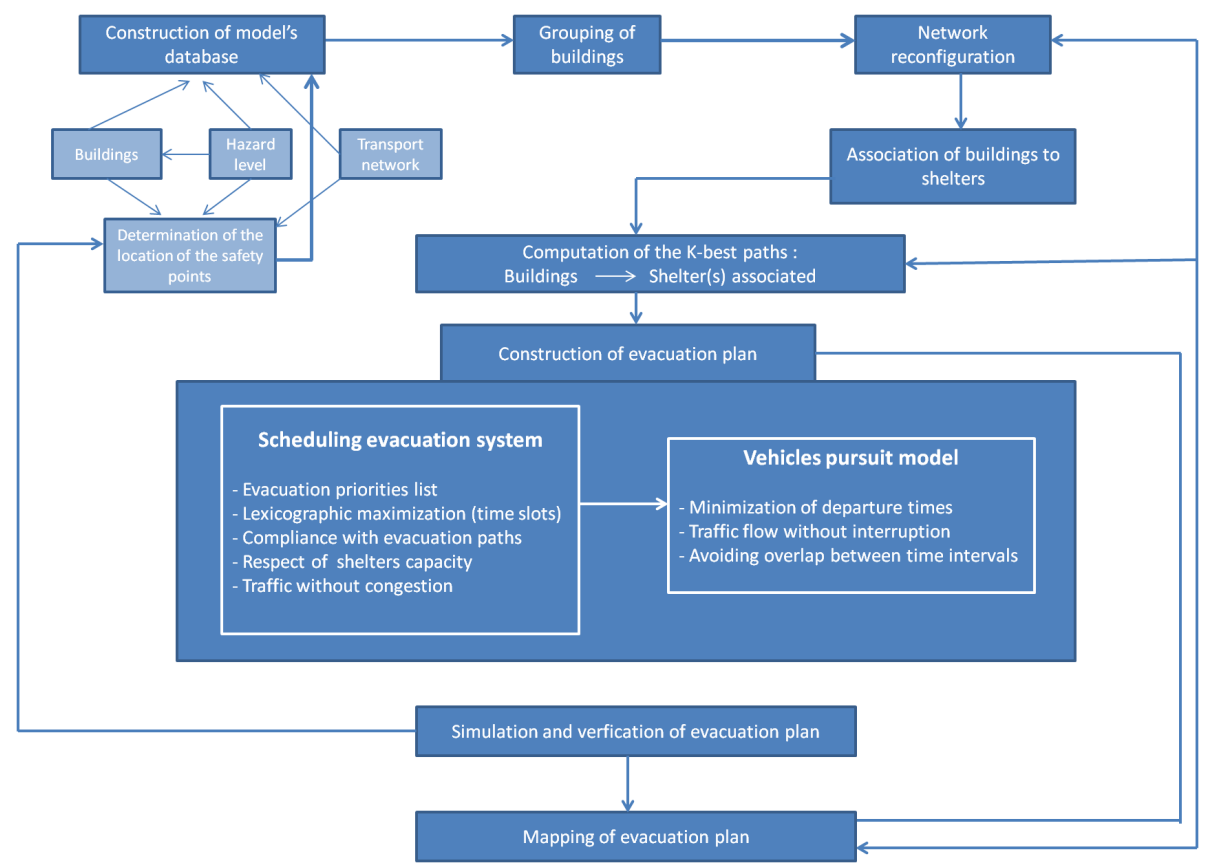

Figure 2. STOM evacuation model.

on the free-flow speed, jam density and number of lanes of roads.

\section{Evacuation model reformulation}

At time of evacuation, inhabitants of a site exposed to hazard must be evacuated through the transport network to the assembly points equipped for this purpose (Southworth, 1991). This operation must be based on a plan computed by an evacuation model under certain constraints (hazard, accessibility, vulnerability, etc.). A definition of the evacuation plan, applied to the case of the tsunami but easily applied to the case of flooding, was given by the Intergovernmental Oceanographic Commission of UNESCO.

The primary aim of an invoked tsunami evacuation plan should therefore be to guide all affected persons along the evacuation routes towards safe places (which are primarily supposed to be outside the reach of tsunami waves but could also be inside the flooded area), also called assembly facilities or emergency shelters, and in time (time span between alarm and arrival of first wave taking into account for each person the distance to the next emergency shelter) (SCHEER, VARELA, EFTYCHIDIS, 2012).

The flowchart in Fig. 2 shows the steps of the evacuation model STOM. The first step is the formation of the spatial input database which includes an urban network database (highways and arterials), buildings to be evacuated (Sect. 3) and safety points (Sect. 4). The next step includes the formation of groups of buildings by network nodes (Sect. 3). The third step concerns the reconfiguration of network according to the preferences of decision-makers (reservation of few specific ways to rescue forces, authorization of no entry, etc.). The fourth step of the model consists of associating one or more shelters with each group of buildings (Sect. 4). The fifth step calculates the $K$-best paths between each group of buildings and each safety point associated. The sixth step computes an evacuation plan based on an evacuation scheduling system and a VPM. The next step simulates and checks the evacuation plan. Finally, a mapping of the final evacuation plan is proposed.

The construction of the database (network, buildings, shelters, population) required for the evacuation model is not addressed here. We focus in this paper on showing only the veritable steps for constructing an evacuation plan.

\section{Grouping of buildings}

The first step is to assign each building to the nearest network node using the airline distance from the centroids of buildings to the extremities of arcs. This assignment results in the formation of groups of buildings by network node. Note that we do not work here on either a microscopic scale (buildings) or a macroscopic scale (neighborhood, area, etc.) but on an intermediate scale, that is to say mesoscopic (group of buildings). Figure 3 shows this step on a part of the Tours valley where buildings that are assigned to the same network node have the same color. 


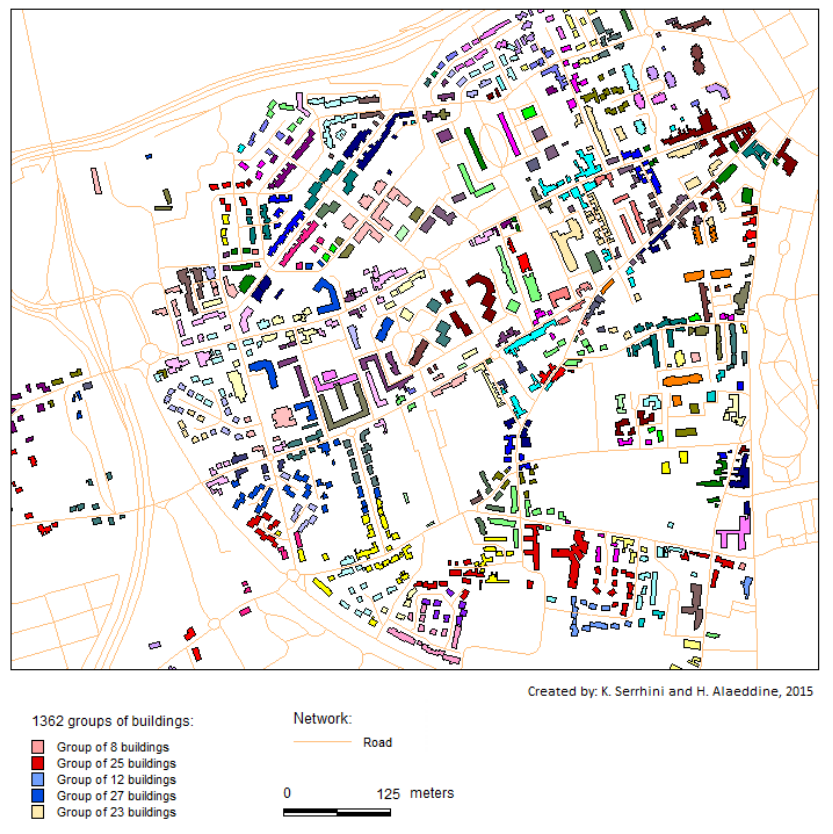

Figure 3. Assignment of buildings to nearest network nodes.

This assignment can be a source of difficulty in traffic if the distance between the centroid of buildings and the nearest network nodes is relatively large. The diagram in Fig. 4 shows that this distance (per interval classes) is low for the majority of buildings in the Tours valley. Otherwise, intermediate nodes must be created in order to minimize that distance.

Henceforth we define "building" as a group of buildings assigned to the same network node.

\section{Safety points}

Safe points, shelters or assembly points are spaces equipped to receive evacuees before or during floods and for a long or short time (Lindell and Prater, 2007). They are determined on the basis of a multi-criteria analysis (vulnerability, bridges, etc.) and with the support of local actors (departmental directorates, territories, prefectures, etc.) (Stage, 2011, 2013). Thus, safe points should provide sufficient reception capacity in terms of people and vehicles, be located in areas providing a rapid response medical assistance and humanitarian aid, etc. The determination of shelters in our model and as we mentioned above is not performed by an optimization approach (selection of a number of shelters among a set of candidates) but directly by the decision-makers. It should be noted that the location and the number of shelters may have significant impact on the evacuation time which, in turn, depends on two elements: the capacity of network and the travel time.

As for buildings, assembly points are also assigned to the closest network nodes. From these assignments we can di-

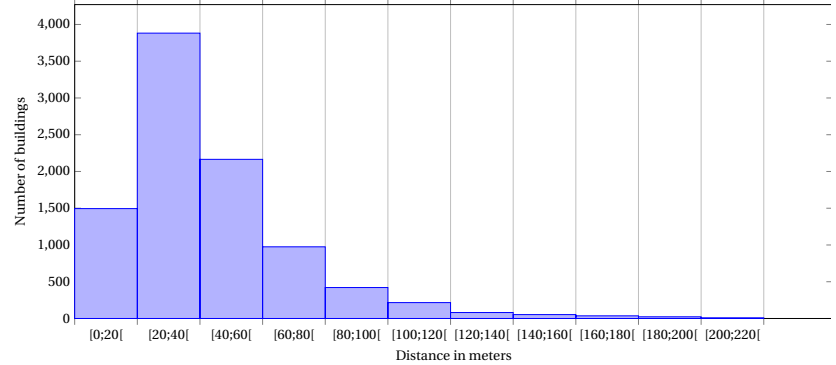

Figure 4. Number of buildings according to their distance from the nearest network nodes.

vide network nodes into three categories: (1) nodes grouping buildings, or node-building; (2) nodes associated with assembly points, or node-shelter; and finally (3) all the remaining nodes that hold nothing.

It should be noted that a node-building can be a crossing node for vehicles coming from other node-buildings. In other words, those vehicles are not authorized to stay in intermediate nodes at the evacuation (Lim et al., 2012).

The last assignment related to the construction of evacuation network corresponds to the association of each building with one or more safety points according to the following criteria: (1) distance to hazard, or "air-line distance"; (2) proximity of buildings from safety points, or "shortest path"; (3) reception capacities of assembly points in terms of vehicles and people; and (4) existence of at least one escape route, in which assignment of buildings to safe points is changed according to flood evolution over time (road cuts).

Figure 5 shows the assignment of buildings of the Tours valley to two safety points (north and south).

\section{Determination of evacuation routes}

The last step to build the evacuation network is to determine the evacuation routes to be taken by the affected population. These paths can be provided as input data for the evacuation model STOM. Otherwise, a paths' computation method is applied to compute a set of k-best paths between each building and each safety point associated (see Alaeddine et al., 2014c). The determination of paths is performed according to two main objectives: the minimization of total clearance time and the maximization of the acceptance degree of these paths by the evacuees. The first objective can be achieved by computing a large number of paths between each origin and destination. However, because the evacuees of an origin will not accept, firstly, a large number of paths and, secondly, long paths in terms of travel time, we determine the paths and their number by a compromise between the two objectives announced (for more details, please see see Alaeddine et al., 2014c). It should be noted that the transport graph excludes certain routes reserved for rescue forces, firefighters, etc., and/or for the evacuation of major buildings (nuclear 


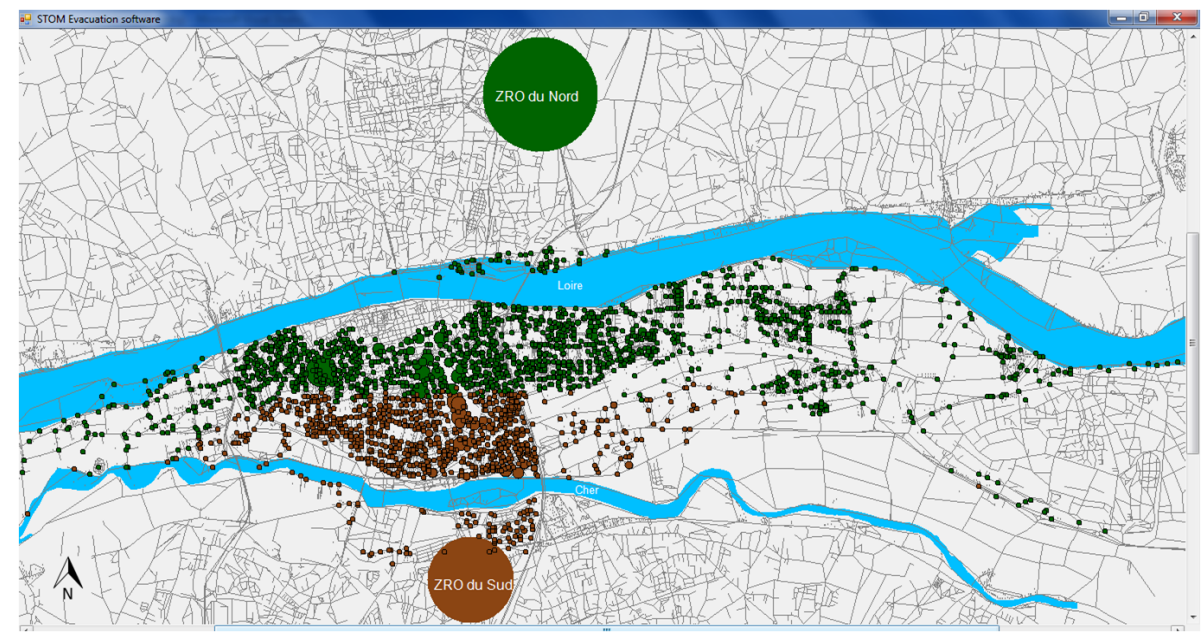

Figure 5. Assignment of buildings to safety points. Buildings in green are assigned to the northern shelter (ZRO du Nord) and the remaining buildings (in brown) are assigned to the southern shelter (ZRO du Sud).

infrastructure, hospitals, retirement homes, etc.). Moreover, a polynomial traffic model is adopted here to compute the capacity (maximal flow rate) of each road link based on jam density, free-flow travel time and number of roads lanes. This traffic model enables to compute the flow-dependent travel time on roads.

In case of evacuation during a disaster, egress routes change over time. Anticipating the state of the network can be helpful to manage traffic and to determine the safest access paths to the impacted areas for rescue services (Versini et al., 2010). We show in the last section of this paper and on a real site (Gien valley) the consideration of the aspect "road cut" in STOM.

\section{Evacuation priority list}

At time of massive evacuation, transportation network does not allow a simultaneous evacuation of all persons located in the risk zone. This requires a complex organizational system to minimize the total evacuation time according to an established priority list.

Lim et al. (2012) identified several factors that influence this priority: the distance of regions from the hazard (hurricane center), the flooding extent and the population density. Based on this priority list, the authors assigned a score per region, defining the level of risk. This level of zonal risk is also established for each building identified by its gravity center or centroid. However, using this method, all buildings in the same area or region have the same risk level.

In this paper, evacuation of buildings is based on a priority list similar to that developed by Lim et al. (2012). However, in addition to criteria of distance from hazard, flooding extent and population density, we take into account other factors including age of the population to be evacuated and distance
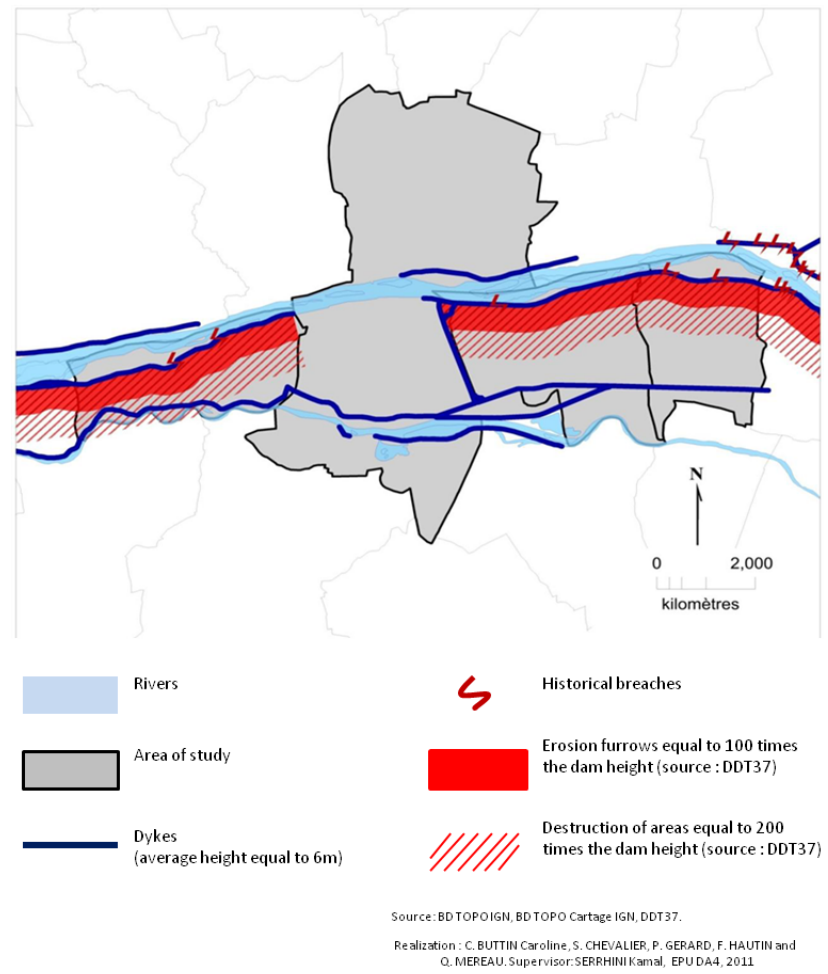

Figure 6. Break levees and potential damage on the Tours valley.

of buildings from both dikes and shelters. The last paragraph of this section gives an explanation for the establishment of one of the priority lists used in STOM.

In addition, our priority list also depends on the spatial scale (region, city, area, building). Indeed, at each level or scale a building has its own priority established according to priorities of higher levels and influenced by one or more 
factors. A combination of factors can be set to determine the priority of buildings at each level.

We present here one of the evacuation priority lists. It is based on the most exposed areas which need to be removed at first. These are the areas which lie just behind the dikes. The map in Fig. 6 shows dike failures and potential damage (in red) on the site of the Tours valley. The dike failures represented are only those previously experienced since it is impossible to predict where a rupture will occur.

We divide each evacuation zone (two evacuation zones, see Fig. 5) into three subzones ([0, 300], [300, 900] and $[900,+])$, where, for example, $[0,300]$ is the area that lies between 0 and $300 \mathrm{~m}$ from the river (see Fig. 7). Moreover, for reasons of organization and behavior of people, it is desirable to evacuate people per neighborhood according to their exposures. Priority evacuation of two buildings located in the same neighborhood at the same level (subzone) is defined according to their distance to rivers. In other words, the priority building is that which is closest to the river. The neighborhood with the largest number of buildings located in the level $[0,300]$ will be evacuated first, followed by the second priority neighborhood of level 300 and so on until the last one. After evacuating the maximum number of buildings (depending on network capacity) located in the first level 300, we turn to the level [ 900 and 900+], repeating successively the same procedure. We repeat these three steps (levels 300, 900 and $900+$ ) until the evacuation of all buildings in all neighborhoods at all levels is completed. Planning the evacuation of buildings at risk requires, therefore, the construction of priority lists specifically tailored for each treated area.

\section{Flow and routing optimization}

The construction of an evacuation plan is the result of a twostage model combining between discrete and continuous process. The first phase in this model is to schedule the evacuation of buildings based on an established priority list. The model assigns, at each time slot ( $1 \mathrm{~h}, 30 \mathrm{~min}$, etc.) and by priority order, the maximum number of vehicles from each building that is not yet evacuated. This model is subjected to road capacity, predetermined evacuation paths and destinations capacity (see evacuation scheduling system, Fig. 2). The second phase of this model focuses on the conversion of the discrete process (time slots) to a continuous one (time intervals) using a developed VPM. This model, which is based on a polynomial traffic model enabling to compute flowdependent travel time on roads, aims to minimize the departure times of vehicles while avoiding overlap between successive time intervals (see vehicles pursuit model, Fig. 2). The congestion on the evacuation network causes, of course, a reduction of the flow entering the network, and therefore queues will be formed on several roads. In STOM, we avoid such a situation using two steps: (1) for each time slot, the capacity (fluid regime) of each road is respected (flow assigned is lower than or equal to the capacity). This capacity is computed using a polynomial traffic model of the form (Ardekani et al., 2011)

$q=k v_{\mathrm{f}}\left(1-\frac{k^{2}}{k_{j}^{2}}\right)$,

where $q$ is the flow, $v_{\mathrm{f}}$ is the free-flow speed, $k$ the density and $k_{j}$ the jam density. The maximal flow rate (or the capacity) $q_{\mathrm{m}}$ is obtained when $\frac{\mathrm{d} q}{\mathrm{~d} k}=0$ (see Alaeddine et al. (2014a), section traffic model). (2) As flow in dynamic network changes over time (increasing of flow followed by a decreasing) and as the set of buildings evacuated varies from one time slot to another, congestion on some roads may occur. We handle this problem by developing a pursuit vehicles model that computes for each origin the minimal evacuation departures times to avoid any traffic jams in the network (for further details, see Alaeddine et al., 2014a). This twostage model was presented in a previous paper (see Alaeddine et al., 2014b, d, a).

\section{Applications and results}

Tests and experiments, as we mentioned before, were performed on two selected study sites: Tours valley (Fr, 37) and Gien valley $(\mathrm{Fr}, 45)$. The first site, protected by a system of dikes, is subjected to a precautionary evacuation due to several factors, among them the relatively high hydraulic flow in the case of a flood-dike breach. Complementary to the first site, we perform an evacuation during a possible crisis on the second site (the Gien valley).

The size of the transportation graph is not limited to a certain threshold in STOM due to the dynamic implementation of data structures. All figures in this section, unless otherwise stated, are generated by STOM evacuation software developed as part of this project ${ }^{2}$.

\subsection{Descriptive indicators of the network}

In this section, we provide the size of graphs of the two study sites as well some descriptive indicators on the transport network of the site of Tours valley.

We represent the size of the graphs of the two sites through their connectivity index $\beta$, which establishes the relationship between the number of links and the number of nodes. ${ }^{3}$ This index indicates, to some extent, the connectivity of network.

\footnotetext{
${ }^{2}$ The tests are performed on an HP Pavilion dv6, Windows 7, 4 GB RAM, Intel (R) Core (TM) i5-2410M, 2.30 GHz.

${ }^{3}$ Many nodes of the graphs only serve to describe the geometry of road (curves). In a graph where edges are straight lines (crow flies), the number of nodes must be reduced. However, it should be noted that these intermediate nodes have helped us a lot to build groups of buildings by assigning each building to the nearest network node.
} 


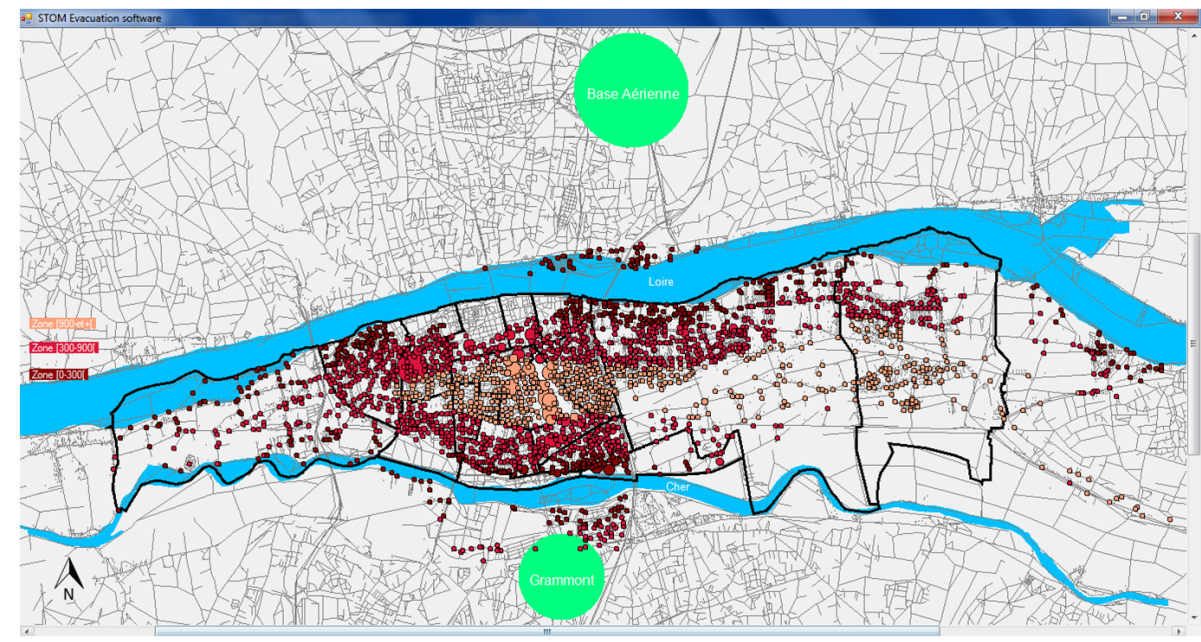

Figure 7. Division of each of the two zones (relative to the two rivers) into three subzones. Zone $[0,300]$ is the area that lies between 0 and $300 \mathrm{~m}$ from the river.

Normally it ranges between 0.5 and 3 (Sharma and Binda, 2007). The numbers below show that the networks of the two sites of study (Tours and Gien) are approximately $220 \%$ connected (Bhaduri, 1992):

$\beta=\frac{L}{S}$,

where $L$ is number of nodes and $S$ is number of arcs.

$$
\begin{aligned}
& -\beta_{\text {Tours }}=\frac{44814}{19997}=2.241 \\
& -\beta_{\text {Gien }}=\frac{5813}{2567}=2.264
\end{aligned}
$$

Capacity or maximal flow rate on roads is a very important element for building an evacuation plan. It is computed by a polynomial traffic model based on the free-flow speed, jam density and number of lanes of road links. Figure 8 shows the capacity (number of vehicles per hour) computed on the site of Tours valley.

\subsection{Preventive evacuation of the Tours valley}

The scenario of dam failure is not considered, as we mentioned previously, in the Tours valley because of the very high flood flows on this site. Given the impossibility of estimating the accessibility of roads during the flood, we focus only on the preventive evacuation. The simulation of the evacuation plan presented here is based on a priority list which is in turn based on the exposure of people per district (see Sect. 6). The preliminary steps are illustrated by Figs. 9 and 10 while the evacuation scheduling per time slot is illustrated by Fig. 11. Figure 9a shows the four levels of hazard on this site while Fig. 9b illustrates the exposure of original buildings based on the destruction zones relative to historical dam failures (see Fig. 6). The grouping of original buildings (by assigning each original building to the nearest

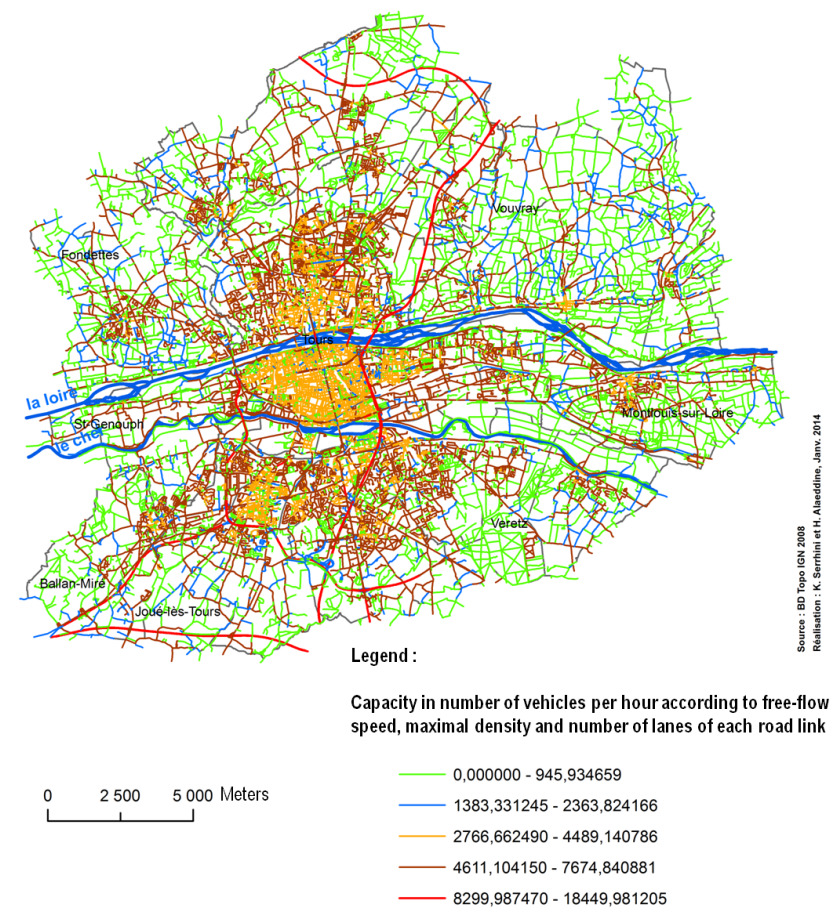

Figure 8. Capacity of roads according to free-flow speed, jam density and number of lanes on roads.

network node) and the association of each building to one shelter is given in Fig. 10b. Figure 10b shows the evacuation network constituent of the three best paths $(K=3)$ computed between each origin and destination. The evacuation priority of buildings per districts based on destruction zones is given in Fig. 10c (see also Sect. 6 and Fig. 7). 

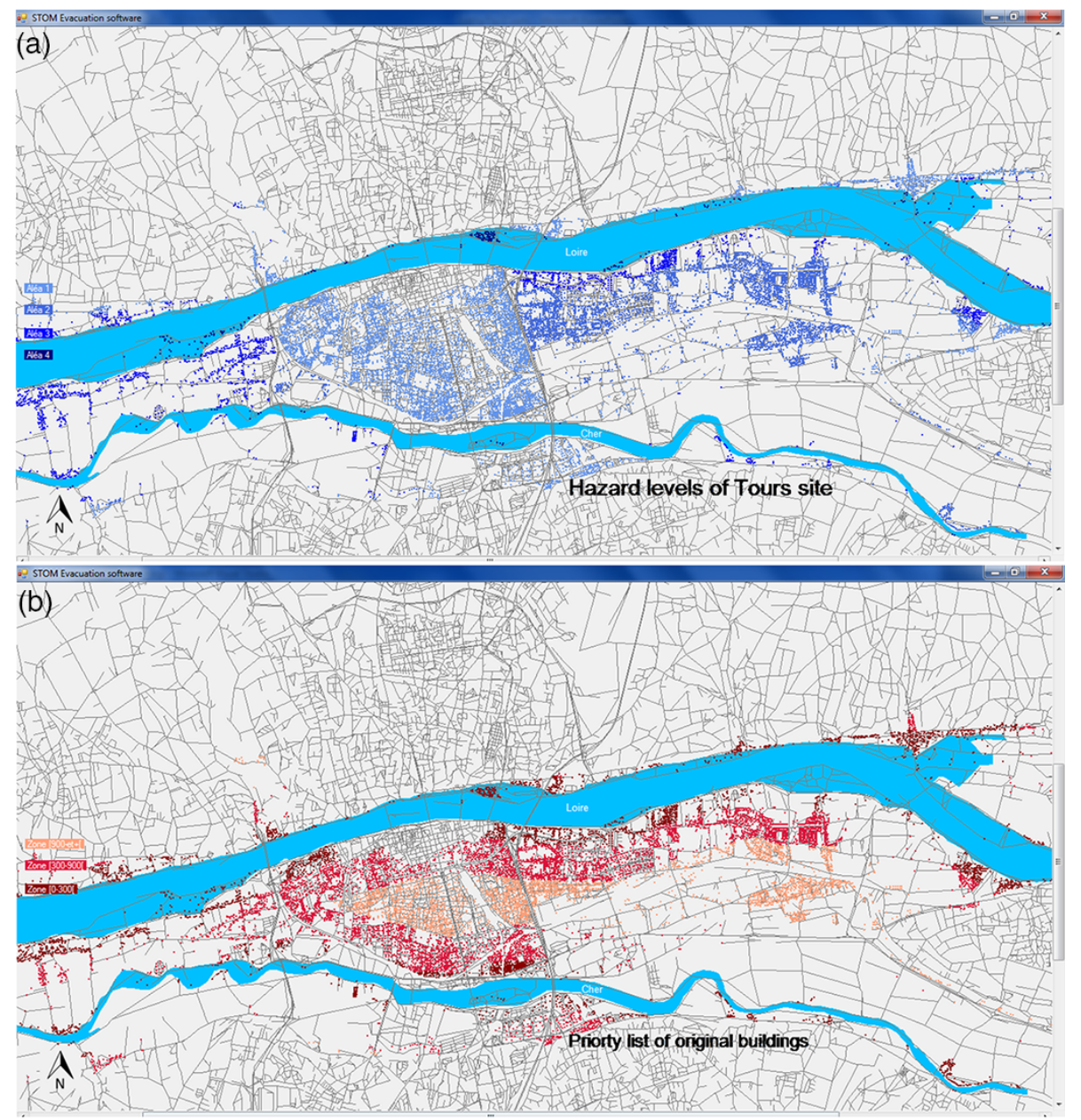

Figure 9. The preliminary steps for the construction of evacuation plan I: (a) shows the hazard levels while (b) illustrates the destruction zones and the assignment of priority to buildings.

In Fig. 11, the different colors of each assembly point (rotation in the direction of clockwise) show the evacuation order of buildings associated to it.

This visualization will be strengthened in the following by another representation showing the importance of the evacuation based on the exposure of people per district.

\section{Evacuation scheduling based on exposures of districts}

For illustration purposes, we focus only on the evacuation of the center of the Tours valley: the city of Tours. Figure 12 shows the evacuation of buildings per districts according to the established priority list (see Fig. 7). The buildings are arranged in descending order of evacuation priority and each color corresponds to a district.

Figure 13 shows more clearly the evacuation of neighborhoods by their levels of exposure. We note that, at each time slot, the neighborhoods located in the first level of danger (band of $300 \mathrm{~m}$ located directly behind the dike, see Fig. 7) are first removed (Beaujardin), followed by those of the sec- ond level (La Fuye Velpeau) and finally the neighborhoods of the third level. The three different colors (red, yellow and blue) represent the three areas of exposure (see Sect. 6).

Figure 13 shows that the evacuation of all neighborhoods is not consecutive (Beaujardin, Rabelais, etc.). However, buildings with the same level of exposure (destruction zones) in each neighborhood were evacuated in an almost sequential manner (Beaujardin, Febvotte, etc.).

\subsection{Evacuation during the flood of the Gien valley}

The evacuation of the Gien valley can take place during a flood crisis since it concerns a slow flooding. In this section we test the evacuation model STOM during the crisis management in the Gien valley, complementing its application in the Tours valley (preventive evacuation). 

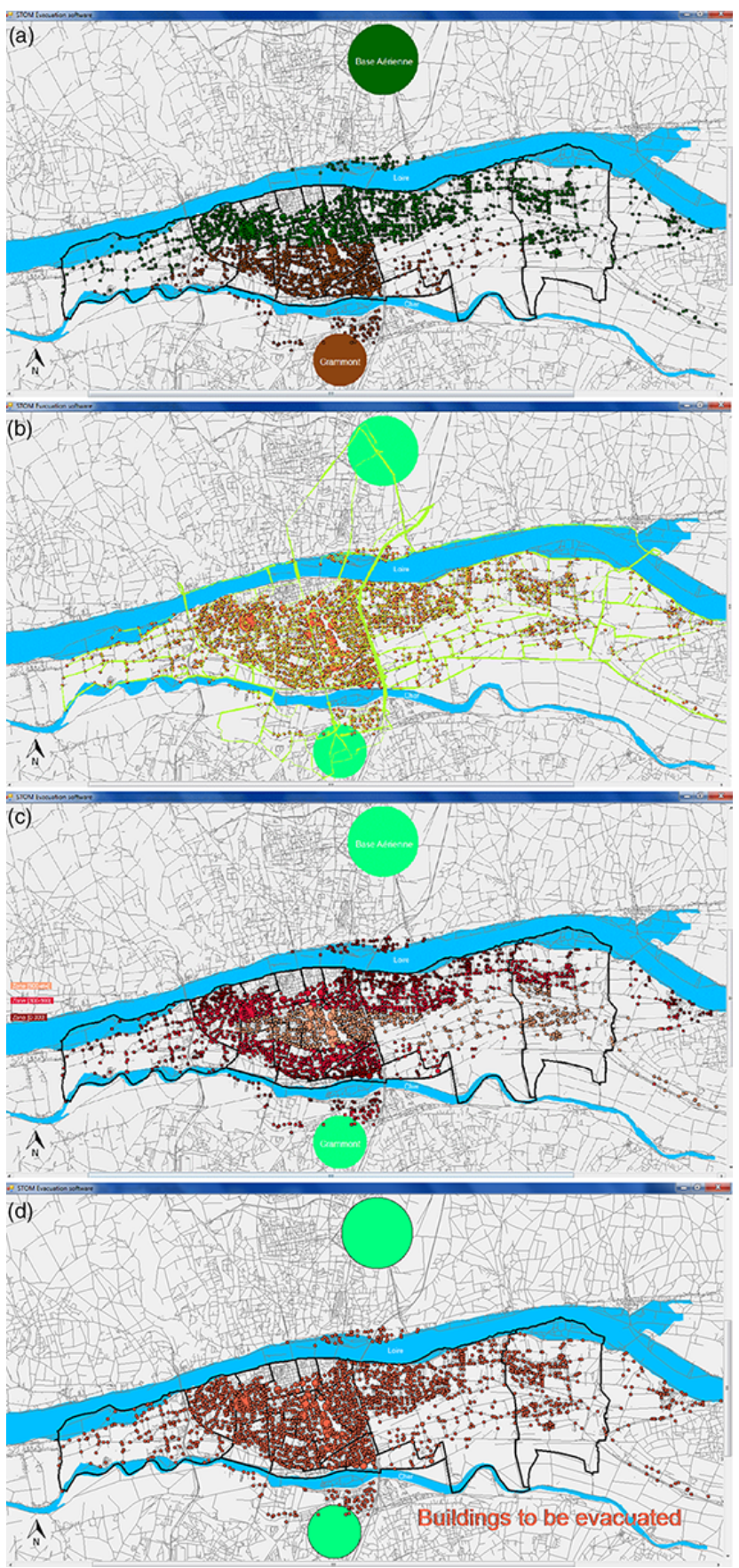

Figure 10. The preliminary steps for the construction of evacuation plan II: (a) grouping of original buildings and association of buildings (groups of original buildings) to safety points. (b) Calculation of three best paths between buildings and safe points. (c) Establishment of priorities list according to destruction zones. (d) Buildings to be evacuated.

\subsubsection{Dynamic of hazard}

The dynamic of hazard over time on the second site is illustrated in Fig. 14. We note the continued accessibility of cer-
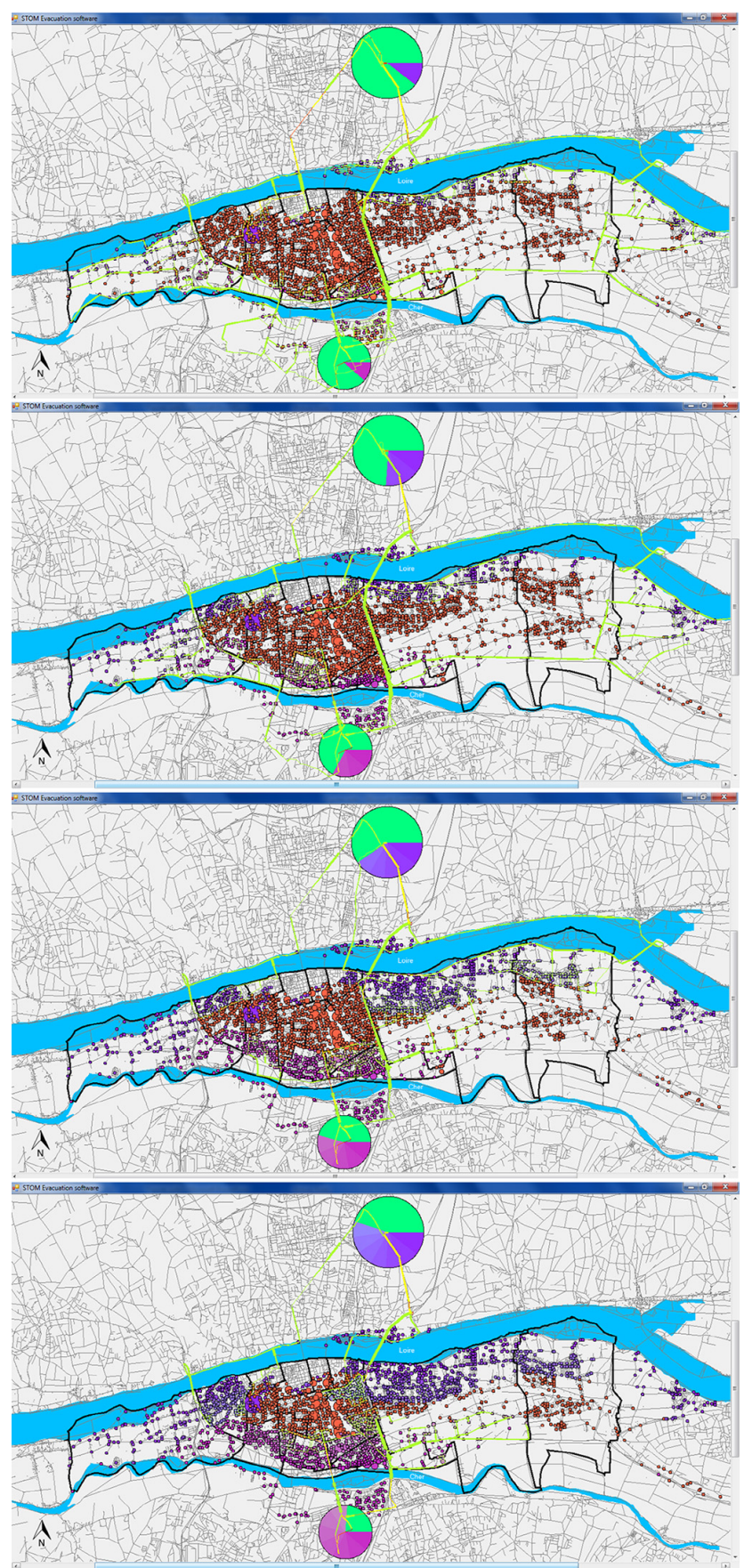

Figure 11.

tain network roads even after $107 \mathrm{~h}$ from the beginning of the flood, allowing for a possible evacuation of some buildings not yet evacuated. 


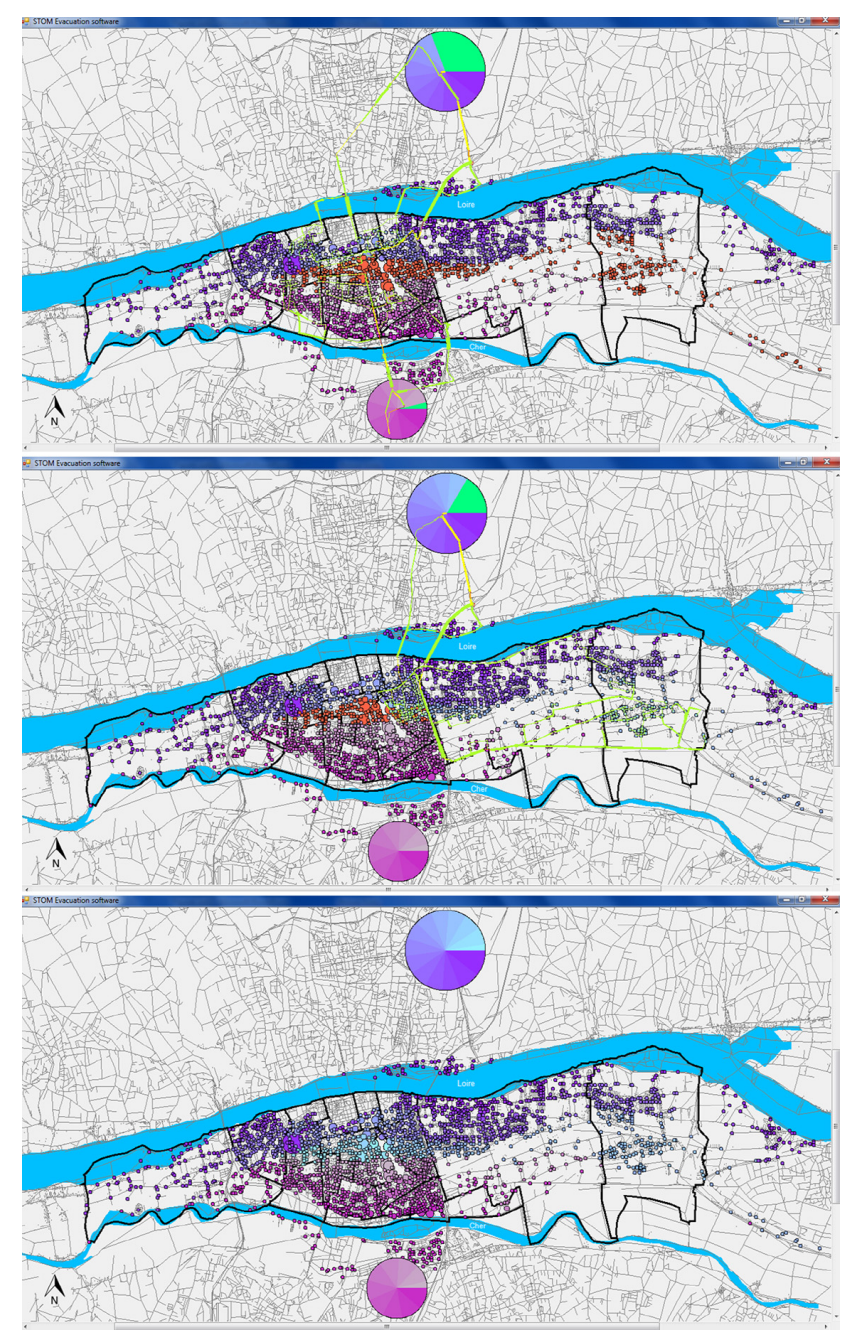

Figure 11. Evacuation scheduling of the Tours valley. Each subfigure shows the evacuated buildings and the paths taken during the slot itself.

\subsubsection{Simulation of the evacuation of the Gien valley: network almost submerged}

This section is devoted to the simulation of the evacuation of the Gien valley for two time periods (beginning of the flood and $125 \mathrm{~h} \mathrm{later}^{4}$ ).

The evacuation in real time during the crisis is not simulated in STOM because of the lack of dynamic information on the network status. However, this simulation does not seem necessary on this site since it is not a mass evacuation. The time slot chosen to illustrate the scheduling of the evacuation is of $1.5 \mathrm{~min}$ because the total evacuation time computed being less than 30 min (Figs. 15-17). This duration is justified by the relatively low number of buildings to be evacuated dispersed along this site. The evacuation paths

${ }^{4}$ Database provided by DREAL Centre, Orléans, France, 45. of buildings do not share many arcs (parallel evacuation per sector).

Figures 15a and 17a represent two cases of buildings: the remaining buildings to be evacuated and the buildings considered isolated. The latter are the buildings that can not be evacuated (we assume they were evacuated earlier) after a certain time from the beginning of the flood, because the area to which they belong is already submerged ${ }^{5}$. The area shown in blue on the network corresponds to $\mathrm{HKW}^{6}$ and not to the progress of the level of water over time. We are interested in representing primarily the isolated buildings (e.g., at $t=127 \mathrm{~h}$ ) to show the dynamics of the hazard. Thus, Figs. $15 \mathrm{~b}$ and $17 \mathrm{~b}$ illustrate the assignment of buildings to safety points with an initial percentage of $50 \%$. This threshold (50\% of the total number of evacuees) probably is not met due to network disconnection (areas submerged). Figures $16 \mathrm{a}$ and $17 \mathrm{c}$ show the three best paths $(K=3)$ computed between each origin and destination pair. This number may suffer a reduction over time for the same reason evoked previously (network disconnection). Finally, Figs. 16b and 18 show the evacuation scheduling per time slot $(1.5 \mathrm{~min})$.

The assignment of buildings to safe points is performed based on the proximity of the latter, and the established priority list is based on the distance of buildings from assembly points (from far to near). We note that evacuation routes computed before or at the beginning of flooding change depending on the evolution of the flood. Figure 17c shows that evacuation paths of some buildings (bottom left) are much longer than those of the same buildings at the beginning of flood (see Fig. 16a).

Moreover the capacity of shelters is not identical after $125 \mathrm{~h}$ (from the beginning of the flood) because of the network disconnection as mentioned above (see Figs. 15b and $17 \mathrm{~b}$ for comparison). In other words, several buildings that are closer to the shelter in the south must be evacuated to the north because there is no available path.

\subsection{Scenarios and validation of evacuation plan in case of incidents}

The two curves in Fig. 19 show the total evacuation duration of the two study sites according to a potential reduction in network capacity. The fall percentage of roads capacity aims to simulate the total evacuation time in case of incidents. This is performed by reducing the capacity of each road of evacuation network. The new capacity is equal to the initial capacity minus the percentage of fall and multiplied by the initial capacity. This simulation aims to determine the validation level of the horizon time. For example, if after a little fall the evacuation time computed exceeds the horizon time given, then the decision-makers should apply some strategies: au-

\footnotetext{
${ }^{5} \mathrm{~A}$ network road is considered submerged (not applicable for evacuation) if the water level is higher than or equal to $30 \mathrm{~cm}$.

${ }^{6}$ Highest known water. Provided by the Prevention Plan Flood Risk.
} 


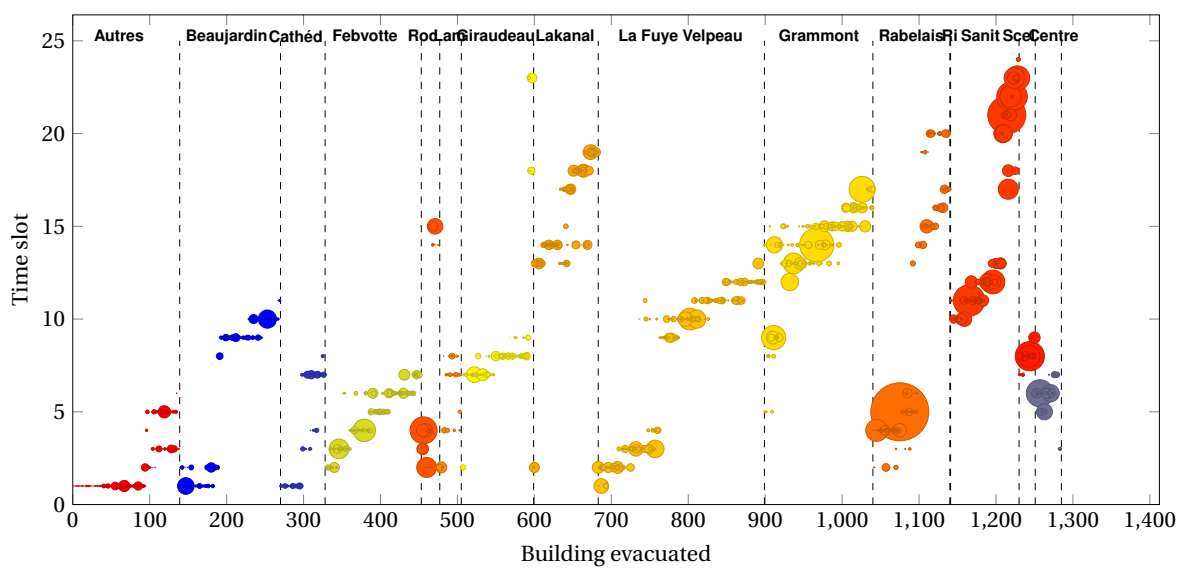

Figure 12. Priority list for the evacuation of buildings in the districts of Tours (exposures of districts according to destruction areas). Each building ( $x$ axis) is represented by a circle where its size indicates the number of vehicles evacuated from this building. Each color represents a district.

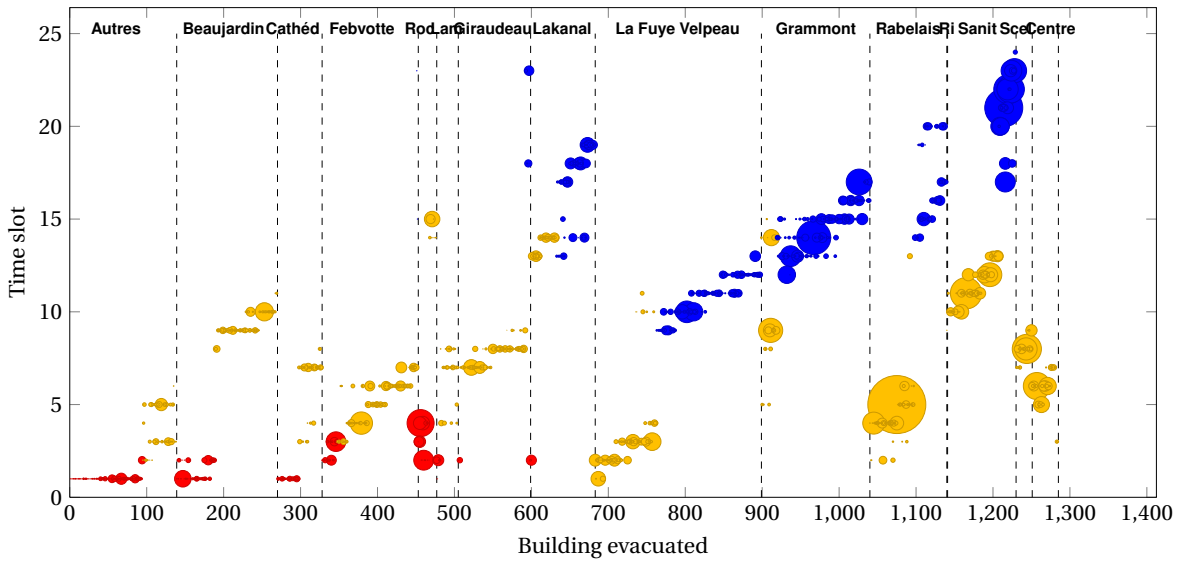

Figure 13. Representation of the evacuation of neighborhoods of the city of Tours based on their exposures. Each building ( $x$ axis) is represented by a circle where its size indicates the number of vehicles evacuated from this building. Each color represents an exposure level $([0,300] ;[300,900] ;[900,+])$.

thorizing no-entry, increasing speed, opening an additional safe area, etc. For reasons of graphical representation, the total evacuation time of the Tours valley with a fall equal to $99 \%$ is set to $100 \mathrm{~h}$, although it is more than $500 \mathrm{~h}$ in reality. The analysis of these two curves shows that the total evacuation time of the Tours valley remains reasonable with a fall of capacity less than or equal to $80 \%$, while that of the Gien valley remains reasonable with a fall less than or equal to $99 \%$.

\section{Conclusions}

The evacuation model STOM can be applied and adapted, if necessary, to any other site requiring an evacuation, whether preventive or during the crisis. To apply a pedestrian evacuation (Chalmet et al., 1982; Hamacher and Tufekci, 1987) (stadiums, ships, etc.), STOM requires a traffic model to compute a pedestrian travel speed according to the number of pedestrians crossing the arc (corridor, passage, etc.). In general, a given evacuation problem (preventive or during the crisis) requires determining the evacuation network (fixed or progressive depending on time), the issues to be evacuated and the safety points to which evacuees will be directed and distributed (Kaisar et al., 2012).

The feasibility of an evacuation plan still faces two challenges related to the behavior of evacuees: respect for evacuation routes and departure dates. Simulation of several scenarios such as delay departure, noncompliance with calculated evacuation paths and accidents allows us to verify to what extent this plan remains robust in terms of total evacuation time. Such simulations should update the evacuation model itself by establishing new constraints to be respected.

Such simulations could also be used to inform people about this risk and compliance with evacuation instructions. 


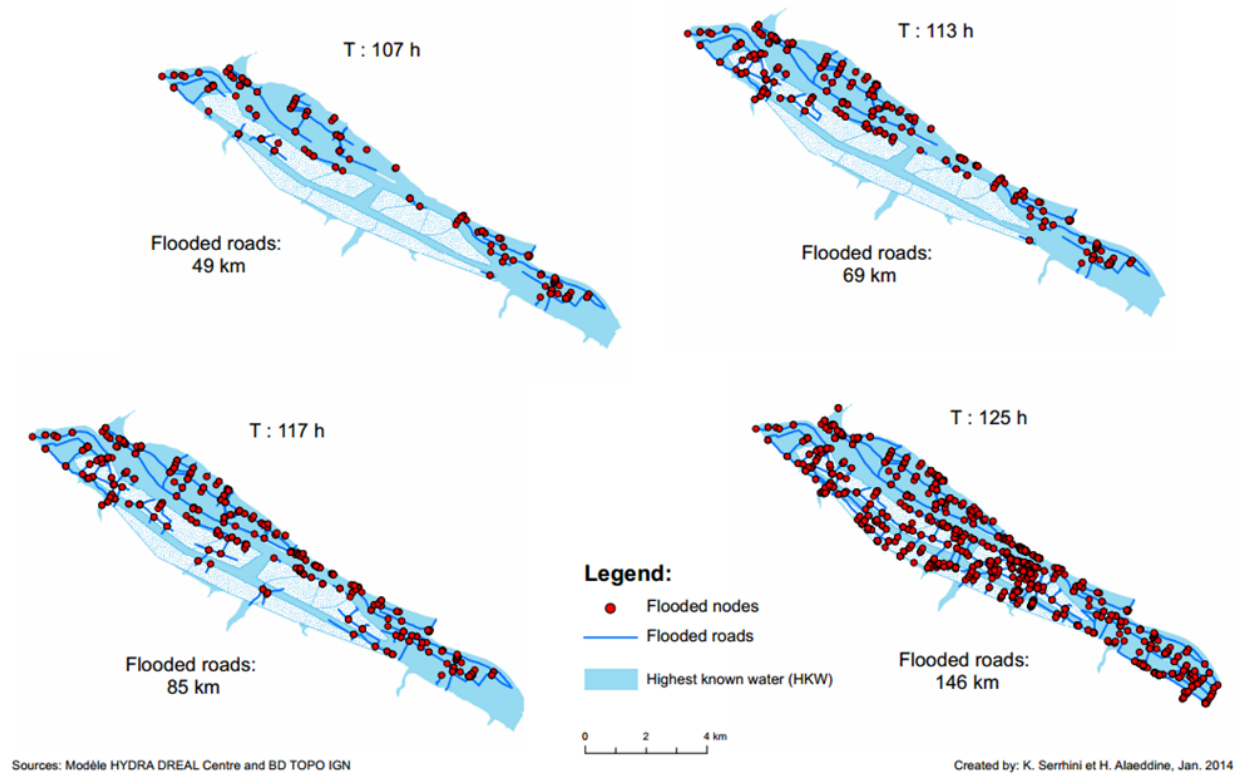

Figure 14. Dynamics of the hazard on the Gien valley's road network.

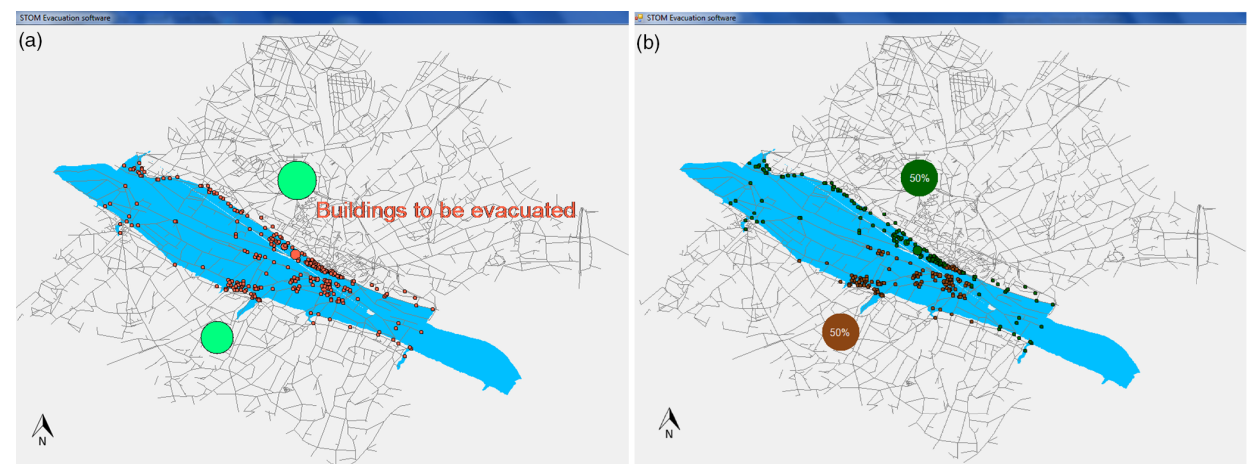

Figure 15. Construction of the evacuation plan at the beginning of the flood: (a) shows the buildings to be evacuated (in red) while (b) shows assignment of buildings to safety points.

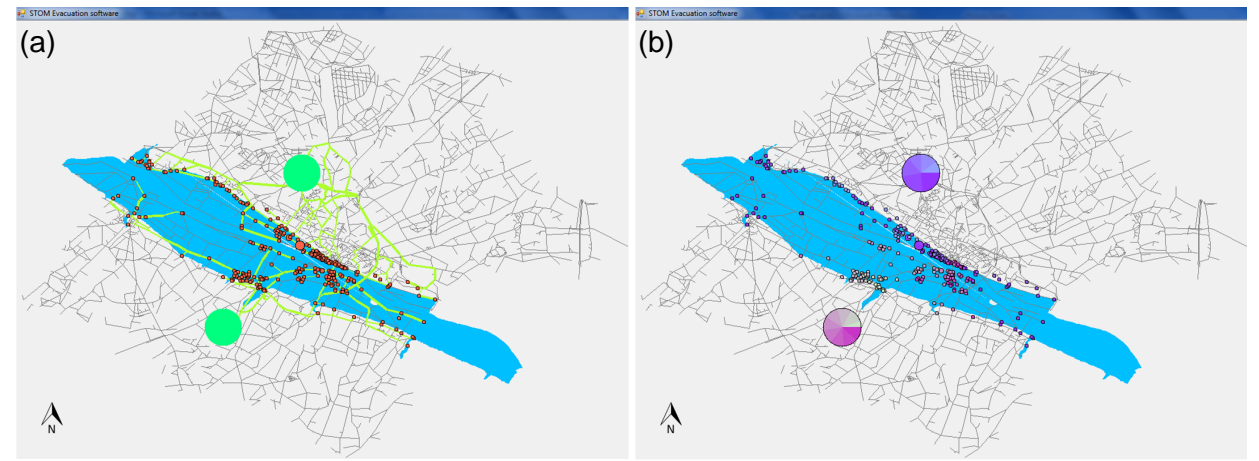

Figure 16. Construction of the evacuation plan at the beginning of the flood: (a) illustrates the three best evacuation paths among buildings and shelters while (b) shows the evacuation of the valley of Gien (each color represents a time slot). 

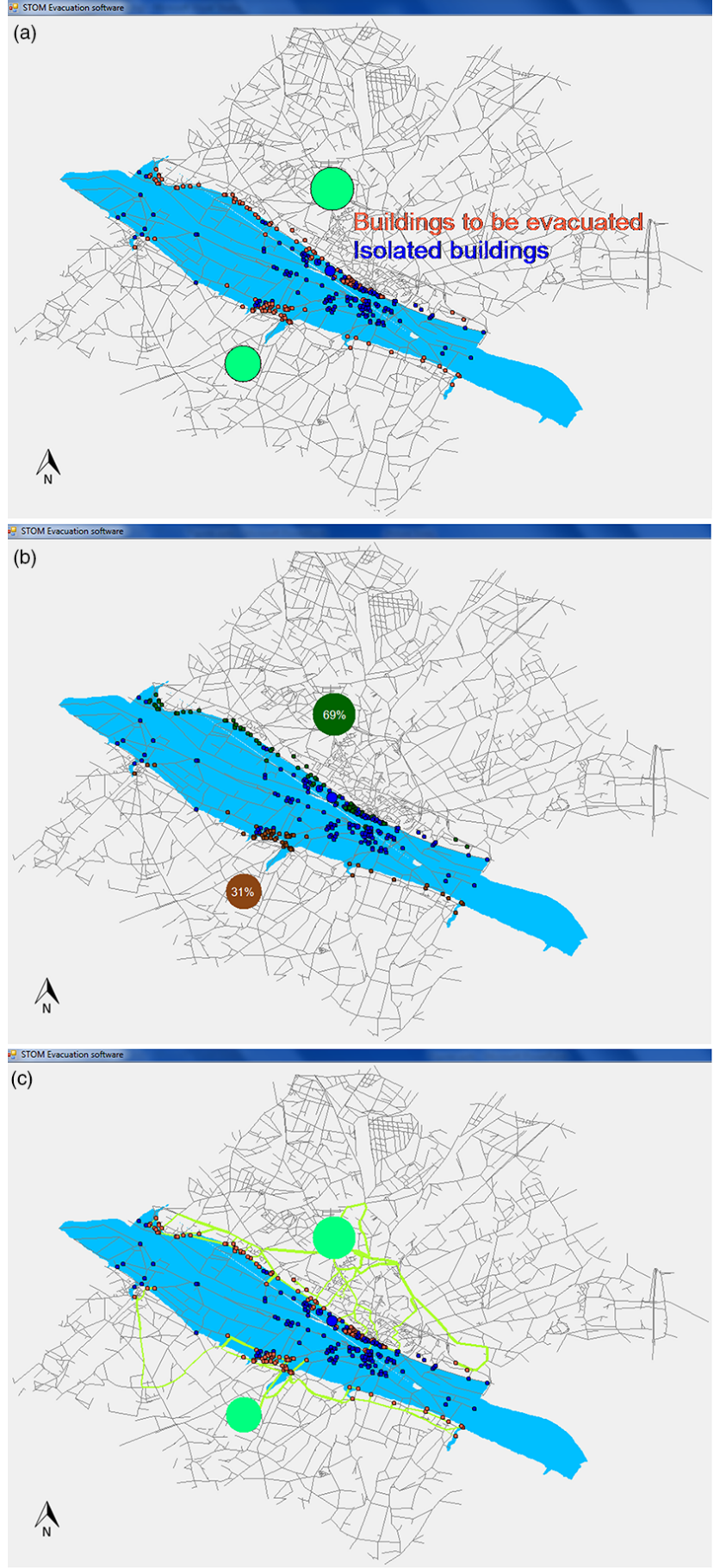

Figure 17. (a) shows the buildings to be evacuated (in red) and isolated buildings (in blue) $125 \mathrm{~h}$ after the beginning of the flood, while (b) shows assignment of buildings to safety points. (c) illustrates the three best evacuation paths among buildings and shelters.

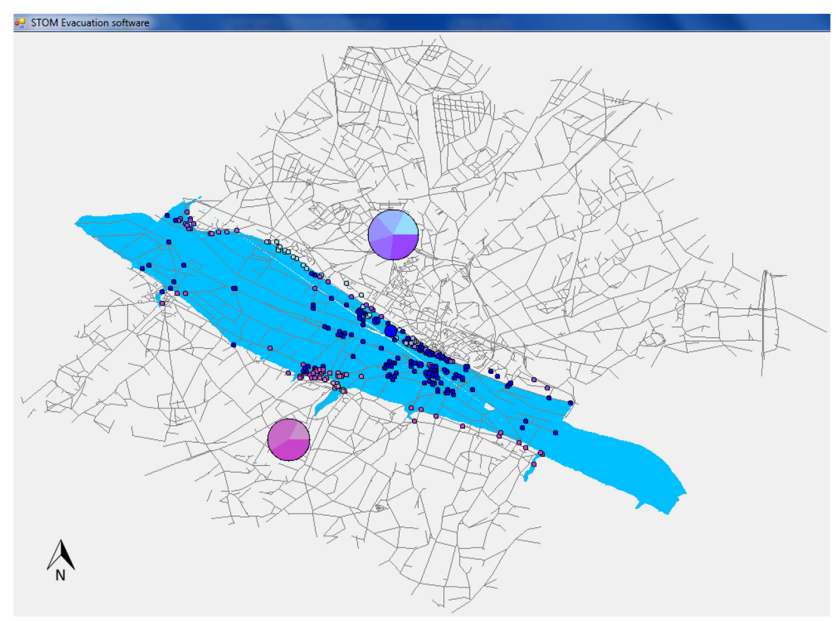

Figure 18. Evacuation of the valley of Gien (each color represents a time slot): construction of the evacuation plan $125 \mathrm{~h}$ after the beginning of the flood.

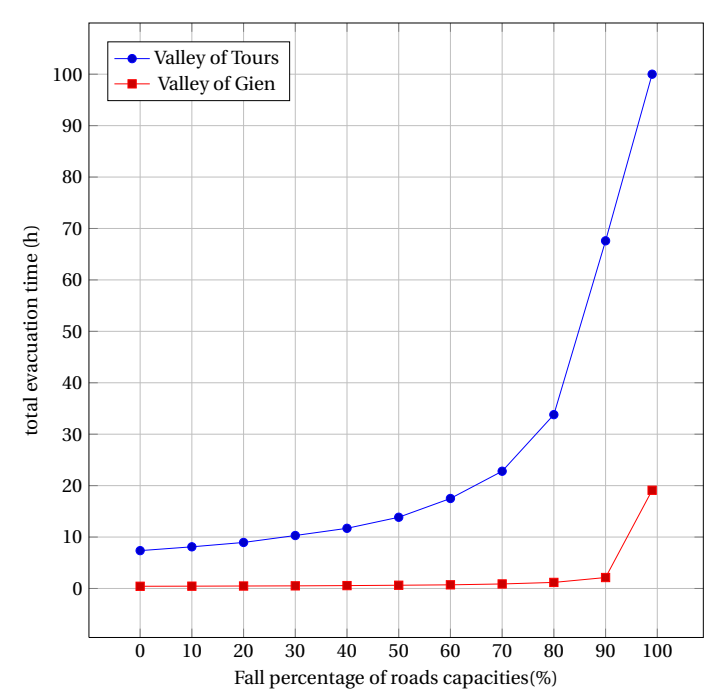

Figure 19. Construction of the evacuation plan $125 \mathrm{~h}$ after the beginning of the floor: evacuation scenarios in case of fall of network capacity.

In addition, a higher number of safety points will result in the diversity of k-best paths which in turn enables us to minimize the total evacuation time and to guarantee a high acceptance level of the evacuation plan by the concerned population. In this case, the evacuation plan is similar to a parallel evacuation of several urban areas (neighborhoods, islands, etc.).

As for the evacuation priorities, several tests were carried out according to different established priority lists. Those were based on a combination of several criteria such as proximity to the hazard of flooding, the age of the population, etc. Total evacuation times provided remain very close to the various priority lists. This would give the crisis management 
actors more flexibility in prioritizing the evacuation order of the population and neighborhoods.

Of course, the validation of the evacuation plan computed also requires the realization of real evacuation exercises by policymakers. From a scientific point of view, these exercises should validate not only the provided results but also the model input data. Among others, the total evacuation time, a measure of the risk, should meet the deadlines of a preventive evacuation. If this condition is not achieved, in order to minimize the total evacuation time decision-makers can apply strategies to change direction of movement, increase speed on certain network roads, open additional safe areas, etc. Finally, the construction procedure of evacuation plan should be regularly updated according to the evolving issues located in flood areas.

Lastly, mapping of evacuation plan carried out by STOM evacuation software requires further development in order to make it more operational (Meyer et al., 2012). Research on this topic is ongoing.

Acknowledgements. We would like to thank LA REGION CENTRE (France) and FEDER (Europe) for funding this research. Also our thanks for the editor Thomas Glade and the two anonymous referees for assessing this paper.

Edited by: T. Glade

Reviewed by: two anonymous referees

\section{References}

Alaeddine, H., Maïzia, M., Serrhini, K., and Néron, E.: A mezoscopic vehicles pursuit model for managing traffic during a massive evacuation, University of Tours, Tours, France, 2014a.

Alaeddine, H., Néron, E., Serrhini, K., and Maïzia, M.: A novel polynomial algorithm for the lexicographic maximum dynamic flow problem with several sources applied to evacuation planning, University of Tours, Tours, France, 2014b.

Alaeddine, H., Serrhini, K., Maïzia, M., and Néron, E.: Finding the K-best paths in evacuation network, University of Tours, Tours, France, 2014c.

Alaeddine, H., Serrhini, K., Néron, E., and Maïzia, M.: Traffic assignment algorithms for planning a mass vehicular evacuation, University of Tours, Tours, France, 2014d.

Ardekani, S., Ghandehari, M., and Nepal, S.: Macroscopic speedflow models for characterization of freeway and managed lane, The University of Texas, Department of Civil Engineering, Arlington, USA, 2011.

Bhaduri, S.: Transport and regional development, Indian Council of Social Science Research, Concept Publishing Company, India, 1992.

Bormanna, A., Kneidl, A., Koster, G., Ruzika, S., and Thiemannb, M.: Bidirectional coupling of macroscopic and microscopic pedestrian evacuation models, Safety Science, 50, 1695-1703, 2012.

Bretschneider, S. and Kimms, A.: Pattern-based evacuation planning for urban areas, Eur. J. Operat. Res., 216, 57-69, 2012.
Bretschneidera, S. and Kimms, A.: A basic mathematical model for evacuation problems in urban areas, Transport. Res. Pt. A, 45, 523-539, 2011.

Caloz, R. and Collet, P. D.: Analyse spatiale de l'information géographique, Presses polytechniques et universitaires romandes, Presses Polytechniques et Universitaires Romandes, collection Ingénierie de l'Environnement, Lausanne, France, 2011.

Chalmet, L., Francis, R., and Sanders, P.: Network Models for Building Evacuation, Management Science, 28, 86-105, 1982.

Chapelon, L. and Leclerc, R.: L'accessibilité ferroviaire des villes françaises en 2020, Paris: La documentation française, Coll. Dynamique des territoires, Paris, France, 2007.

Dixit, V.: Hurricane evacuation : Origin, route and destination, M. Tech., Indian Institute of Technology, Delhi, 2005.

Fuchs, S., Heiss, K., and Hübl, J.: Towards an empirical vulnerability function for use in debris flow risk assessment, Nat. Hazards Earth Syst. Sci., 7, 495-506, doi:10.5194/nhess-7-4952007, 2007.

Geurs, K. and Wee, B.: Accessibility evaluation of land-use and transport strategies: review and research directions, J. Transport Geogr., 12, 127-140, 2004.

Hamacher, H. and Tjandra, S.: Mathematical Modelling of Evacuation Problems: A State of Art, Beritche des Fraunhofer Istitut Techno- und Wirtschaftsmathematik Nr. 24, internal report, Germany, 2001.

Hamacher, H. and Tufekci, S.: On the use of lexicographic min cost flows in evacuation modeling, Department of Industrial and System Engineering, University of Florida, Gainesville, Florida, 1987.

Kaisar, E., Hess, L., and Palomo, A.: An Emergency Evacuation Planning Model for Special Needs Populations Using Public Transit Systems, J. Publ. Transport., 15, 45-70, 2012.

Lammel, G., Grether, D., and Nagel, K.: The representation and implementation of time-dependent inundation in large-scale microscopic evacuation simulations, Transport. Res. Pt. C, 18, 84-98, 2010.

Lim, G., Zangeneh, S., Baharnemati, M., and Assavapokee, T.: A capacitated network flow optimization approach for short notice evacuation planning, Eur. J. Operat. Res., 223, 234-245, 2012.

Lindell, M. and Prater, C.: Behavioral Assumptions in Evacuation Time Estimate Analysis, International Conference on Urban Disaster Reduction, Taiwan, China, Taipei, 2007.

Mathis, P., Chapelon, L., Serrhini, K., Baptiste, H., Decoupigny, F., Khaddour, O., Larribe, S., L'Hostis, A., Decoupigny, C., and Appert, M.: Graphs and Networks: Multilevel Modeling, Geographical Information System Series, ISTE, France, 2007.

Matisziw, T. and Murray, A.: Modeling s-t Path Availability to Support Disaster Vulnerability Assessment of Network Infrastructure, Comput. Operat. Res., 36, 16-26, 2009.

Meyer, V., Kuhlicke, C., Luther, J., Fuchs, S., Priest, S., Dorner, W., Serrhini, K., Pardoe, J., McCarthy, S., Seidel, J., Palka, G., Unnerstall, H., Viavattene, C., and Scheuer, S.: Recommendations for the user-specific enhancement of flood maps, Nat. Hazards Earth Syst. Sci., 12, 1701-1716, doi:10.5194/nhess-121701-2012, 2012.

Naghawi, H.: Transit-based emergency evacuation modeling with microscopic simulation, PhD BS, The University of Jordan, MS, The University of Jordan, Jordan, 2010. 
Naser, M. and Birst, S.: Mesoscopic Evacuation Modelin for Smallto Medium-Sized Metropolitan Areas, Advanced Traffic Analysis Center, Upper Great Plains Transportation Institute, North Dakota State University, Fargo, 2011.

Patouillard, S., Auger, N., and Maurin, J.: Les renforcements de digues en Loire moyenne, mise en perspective des techniques et expérimentation, Digues maritimes et fluviales de protection contre les submersions, Deuxième colloque national, Aix en Provence, 2013.

Plattner, Th.: Modelling public risk evaluation of natural hazards: a conceptual approach, Nat. Hazards Earth Syst. Sci., 5, 357-366, doi:10.5194/nhess-5-357-2005, 2005.

Powell, W., Jaillet, P., and Odoni, A.: Stochastic and dynamic networks and routing, in: Handbooks in Operations Research and Management Science - Network Routings, 8, chapter 3, edited by: Ball, M. O., Elsevier, North-Holland, 1995.

Saadatsresht, M., Mansourian, A., and Talaei, M.: Evacuation planning using multiobjective evolutionary optimization approach, Eur. J. Operat. Res., 198, 305-314, 2009.

Sharma, H. and Binda, P.: Modeling in Resource Management and Environment Through Geomatics, Concept, 2007, xiv, p. 304, figs, tables, Concept Publishing Co, 2007.

Southworth, F.: Regional Evacuation Modeling: A State-of-the-Art Review, Oak Ridge National Laboratory, USA, 1991.
Stage: Plan d'évacuation massive du val de Tours en cas de crue majeure de la Loire, Stage collectif dirigé par M. Serrhini Kamal; Réalisation: Buttin, C., Chevalier, S., Gerard, P., Hautin, F., Mereau, Q., EPU DA4, Université françois-Rabelais de Tours, Ecole polytechnique, Département Aménagement, France, 2011.

Stage: Plan d'évacuation de la population du val de Gien en cas d'inondation majeure de la Loire. Stage collectif dirigé par M. Kamal Serrhini; Réalisation: Bouyneau, M., Ludwig, J., Odier, H., Ramond, L., EPU DA4, Université françois-Rabelais de Tours, Ecole polytechnique, Département Aménagement, France, 2013.

Stepanov, A. and Smith, J.: Multi-objective evacuation routing in transportation networks, Eur. J. Operat. Res., 198, 435-446, doi:10.1016/j.ejor.2008.08.025, 2009.

Trani, A.: Introduction to Transportation Engineering, Traffic Flow Models, Virginia Polytechnic Institute and State University Blacksburg, Virginia, 2009.

Versini, P.-A., Gaume, E., and Andrieu, H.: Assessment of the susceptibility of roads to flooding based on geographical information - test in a flash flood prone area (the Gard region, France), Nat. Hazards Earth Syst. Sci., 10, 793-803, doi:10.5194/nhess10-793-2010, 2010.

Yusoff, M., Ariffin, J., and Mohamed, A.: Optimization approaches for macroscopic emergency evacuation planning: A survey, Conference Proceeding: Information Technology, 2008, ITSim 2008 , International Symposium, Kuala Lumpur, Malaysia, 2008. 